\title{
ON SELECTION FOR INBREEDING IN POLYGYNOUS ANIMALS
}

ROBERT H. SMITH

Wildlife Management Group, Department of Zoology, University of Reading, Berkshire RG6 2AJ

Received 11.iii.11

\section{SUMMARY}

It is assumed by many zoologists that most animals avoid inbreeding because of the associated deleterious effects. The breeding behaviour of fallow deer is described and shown to make a father-daughter incest likely. By treating incest as a form of altruistic behaviour on the part of females, an inclusive fitness argument is developed to account for incest in polygynous species. It is shown that a substantial (1/3) reduction in individual fitness is required if incest is to be selected against.

\section{INTRODUGTION}

INBREEDING in animals is generally thought of as being in some sense disadvantageous, particularly when it is as extreme as incest between parents and offspring or between sibs (e.g. Bodmer and Cavalli-Sforza, 1976; Clutton-Brock and Harvey, 1976; Wilson, 1975). On the other hand botanists do not seem too surprised that there are plants in which selffertilisation is normal or even obligatory (Berry, 1977). Detrimental effects of inbreeding are well known to animal breeders and are usually thought to result from increased homozygosity of deleterious recessive alleles. Many zoologists assume that the detrimental effects of inbreeding have, by natural selection, led to the evolution of outbreeding mechanisms. Thus zoologists tend to look for behavioural mechanisms of outbreeding, and often seem to find them. However, so-called outbreeding behaviour is often just dispersal of one of the sexes and other explanations, such as male-female conflict in breeding behaviour or avoidance of competition between parent and offspring, are usually overlooked.

In this paper I question the assumption that selection nearly always operates to encourage outbreeding behaviour and consider how inbreeding can increase fitness. First I describe an incest phenomenon in fallow deer (Dama dama L.) and then suggest an explanation based on an inclusive fitness argument. The two messages which emerge are that male-female conflict in breeding behaviour is sometimes to be expected in polygynous species and that the recent history of a species or a population may be allimportant in determining the evolution of a particular mating system. Of course a degree of inbreeding will occur in any finite population and the effects of inbreeding on genetic variability are very similar to those of random genetic drift in small populations (Wallace, 1968; Cavalli-Sforza and Bodmer, 1971). Therefore, if inbreeding is selected against because it leads to increased homozygosity, then so should be small population size. Wilson (1975) has reviewed the range of effective population sizes in the few species for which reliable data are available, and notes that the numbers range from 
100 down to 10 or even less in most social vertebrates. In a patchy environment, small deme size may be explained if the cost of migration between demes is greater than that of inbreeding depression (Bengtsson, 1978); however, small demes can be a direct result of social behaviour (e.g. Lewontin and Dunn, 1960; Selander, 1970), showing that natural selection does not necessarily produce behaviour which maintains genetic variability.

\section{BREEDING BEHAVIOUR IN FALLOW DEER}

Like many other mammals, fallow deer are polygynous (many females mated by a single male). Females invest a great deal of effort in gestation and lactation which limits the number of offspring to one fawn a year in fallow deer. Males can contribute little to parental care and instead put their resources into fertilising many females (Orians, 1969; Maynard Smith, 1977a; Clutton-Brock and Harvey, 1978). Fallow deer mating is synchronised, probably in response to decreasing day length (Chapman and Chapman, 1975), and the peak of mating activity (the rut) is in the second half of October in Britain. Most fawns are conceived then and born the following June.

Bucks and does live in separate herds for most of the year, coming together only in the rut at traditional rutting stands where bucks compete to determine dominance and 10 or 20 does may congregate and be fertilised by the dominant buck. Male dominance is determined without reference to the females and the females select a rutting stand rather than a particular male. The formation of groups of does at rutting stands may be interpreted as a female strategy which promotes competition amongst males so that a doe is most likely to be fertilised by the strongest, most aggressive male (cf. Cox and le Boeuf, 1977). Fallow deer are very variable in coat colour characteristics which makes them much easier to recognise individually than other deer species. Forestry Commission Rangers report that the same deer are observed to return to the same rutting stand each year (G. Springthorpe, personal communication) and a buck may be dominant at a rutting stand for 3 or 4 years.

The breeding behaviour described above does not in itself lead to inbreeding, although winner-takes-all competition amongst bucks drastically reduces effective population size and hence increases random genetic drift. It is the dispersal pattern of the fawns which makes incest the more or the less likely. Buck fawns stay with their mothers until their antlers begin to grow in their first spring when most of them depart to join buck herds. Almost all will have left their mothers before their first rut. Doe fawns, in contrast, stay with their mothers at least until after their second winter (Chapman and Chapman, 1975), and yearling does are often seen suckling alongside young fawns (unpublished observations). A similar dispersal pattern is found in other deer species (e.g. Hawkins and Klimstra, 1970). Hence the yearling does follow their mothers to rutting stands where they were conceived 2 years previously and are therefore likely to be mated by their own fathers.

\section{A MODEL OF SELECTION FOR INBREEDING}

Although an incestuous mating may reduce the probability of producing a fully viable and fertile fawn, incest increases the reproductive success of 
the doe's father and is therefore a form of altruism on the part of the doe; as the altruistic behaviour is directed towards a close relative, it is reasonable to suppose that incest has evolved through kin selection (Maynard Smith, 1964). Although incest may reduce the probability that a fully fertile fawn will be produced, the coefficient of relationship between mother and fawn will consequently be more than $1 / 2$ because they share the same father. Using Hamilton's (1964) argument, any genetic component in female behaviour which makes incest more likely will be selected for provided that incest increases inclusive fitness.

The argument is quantified as follows for an initially outbred, large population. Assume that non-incestuous mating always results in one offspring (relaxation of this assumption simply means multiplying both sides of equations (1) and (2) by a scaling factor and in no way affects the result). Considering only the contribution to fitness of one breeding season, the contribution to the mother's fitness associated with a successful non-incestuous mating is $1 / 2$ (the coefficient of relationship between mother and fawn). We define a coefficient of inbreeding depression $d$ such that the probability of successfully producing a fully viable and fertile fawn from an incestuous mating is reduced by a factor $1-d$ relative to that from a non-incestuous mating ( $d$ may be the result of decreased viability or fertility or both). A fawn from a father-daughter mating has a coefficient of relationship with its mother of $3 / 4$ and inbreeding behaviour in females will be selected for provided,

$$
\text { or } \quad \begin{aligned}
(1-d) 3 / 4 & >1 / 2 \\
d & <1 / 3
\end{aligned}
$$

Now the coefficient of relationship between a fawn produced from a nonincestuous mating by a doe and the doe's father is only $1 / 4$, so that incest will increase his inclusive fitness if,

$$
\text { or } \quad \begin{aligned}
(1-d) 3 / 4 & >1 / 4 \\
d & <2 / 3
\end{aligned}
$$

Equations (1) and (2) apply quite generally to polygynous and polygamous species so long as the ability of the male to mate with any other available female is unaffected by an incestuous mating. Incest represents altruistic behaviour only on the part of the female because the male does not risk any loss of his individual fitness.

The inclusive fitness argument only gives an approximate solution to the question of how large inbreeding depression can be before there is selection against incest, and strictly only applies when inbreeding is rare and the coefficient of relationship between parent and offspring is 1/2. Maynard Smith (personal communication) has pointed out that, as the coefficient of relationship increases towards 1 in an inbred population, the limiting values of $d$ for males and females converge to $1 / 2$ which is the same as the value for the spread of a gene for selfing in hermaphrodites (Maynard Smith, 1977b). Maynard Smith also noted that, in the case of brother-sister incest, dynamic genetic models show that the critical values of $d$ given by the inclusive fitness method are correct for a rare dominant gene for outcrossing, whereas for a rare dominant gene for inbreeding, the values are 0.583 in sisters and 0.387 in brothers. Unfortunately, father-daughter mating requires a model

43/2-D 
based on partially overlapping generations which cannot be solved analytically. However the critical value $(d<1 / 3)$ for females in an initially outbred population given by the inclusive fitness method provides an estimate of the degree of inbreeding depression which will permit selection for inbreeding behaviour. It is not surprising that the selection pressures on males and females will be different in the early stages of establishment of inbreeding behaviour given that incest is an altruistic act on the part of the female but not the male.

\section{The IMPORTANCE OF BREEDING History}

The coefficient of inbreeding depression will depend both on recent population breeding history and on current selection pressures. Under novel inbreeding, $d$ will initially increase as increased homozygosity brings together deleterious recessive alleles. Continued inbreeding will remove many of these alleles from the gene pool and $d$ may eventually decrease as a new genetic balance is achieved. Whether or not inbreeding behaviour becomes established depends both on the maximum value reached by $d$ and on the change in the inbreeding coefficient. One possibility is that inbreeding and outbreeding are favoured alternately, leading to a stable polymorphism in breeding behaviour (cf. Maynard Smith, 1977b). One reason why $d$ should eventually decrease under inbreeding is that occasional outbreeding can ameliorate increasingly detrimental effects of inbreeding by the introduction of new genes and recombination, a ploy which is well known to animal breeders (Falconer, 1964; Bodmer and Cavalli-Sforza, 1976). A history of enforced inbreeding (e.g. influence of man or catastrophic reduction in population size) may also push $d$ back below the critical level as deleterious recessive alleles are eliminated and recombination leads to a new genetic balance (Berry, 1977). Enforced inbreeding may reveal a substantial genetic load (Muller, 1950) and some demes could become extinct.

I have previously suggested (Smith, 1978) that enforced inbreeding could be the cause of inbreeding behaviour in fallow deer. Fallow deer in Britain are feral and originate from small park herds, mostly imported since the Norman occupation. Inbreeding would be inevitable in small park herds and the consequent elimination of deleterious recessive alleles might have reduced $d$ almost to zero.

\section{Discussion}

The extent to which incest occurs in wild fallow deer needs to be quantified, and a detailed behavioural study of individually marked deer in a forest herd has been initiated and will provide data during the next few years. It is predicted that rutting stands represent demes and hence that there will be more genetic variation between than within demes. Blood samples have been and will continue to be collected from living and culled deer, and electrophoretic separation of isoenzymes will provide a sample of genetic markers such that non-random mating can be tested for, using selection component analysis (Christiansen and Frydenberg, 1973). Controlled crosses have been set up annually since 1976 in large forest enclosures (Smith et al., 1978) to give the basic genetic information necessary to interpret isoenzyme electrophoresis patterns. 
Because the coefficient of relationship between mother and son is the same as that between father and daughter, equations (1) and (2) should also apply to mother-son incest. Why, then, do buck fawns disperse when both they and their mothers might increase their inclusive fitness by incest? A yearling buck has virtually no chance of competing successfully against older bucks in the rut. Therefore by following his mother to a rutting stand, he would merely increase competitive pressure on his father and decrease one component of his inclusive fitness. Although the mother is as closely related to her son as to her father, she is more likely to produce vigorous offspring by mating with her father who has already proved himself in competition with other bucks. These arguments may apply to other mammals where it is usually the young males which disperse before breeding (e.g. Itani, 1972; Glutton-Brock and Harvey, 1976). Obviously equations (1) and (2) must be interpreted in the context of the social organisation of particular species which, in mammals, is often a male dominance hierarchy correlated with age. Thus dispersal of young males in polygynous species may represent, not incest avoidance, but a response to kin selection for father-daughter incest and the consequent avoidance of father-son competition. Male dispersal will naturally lead to some outbreeding and reduce the rate of fixation of deleterious recessives, but the concept of occasional outbreeding as part of a largely incestuous breeding system is substantially different from that of dispersal having evolved in order to reduce the likelihood of inbreeding (Maynard Smith, 1977b). Two examples of mammals which this model seems to fit closely are the prairie deermouse, in which the observed high degree of inbreeding is mainly accounted for by father-daughter matings (Howard, 1949), and the Japanese macaque (Itani, 1972).

There may also be selection for inbreeding for reasons other than a direct increase in inclusive fitness. Disruptive selection can reduce inbreeding depression and may even make $d$ negative, e.g. selection for reduced gene flow in heavy metal tolerant plant populations on spoil heaps (Bradshaw, 197I). Wilson (1975, 1976) has suggested that co-operation amongst kin within inbred groups may offset inbreeding depression; incest is well documented in some co-operative hunters such as the wolf (Sullivan, 1978) and the coyote (McMahan, 1978) but avoided in lions (Bertram, 1976). Unfortunately it is not easy to estimate the relevant parameters in real populations in order to evaluate the different selective forces involved. The coefficient of inbreeding depression $d$ presents particular estimation problems since inbreeding depression measured in terms of effects on particular characters is not necessarily a depression in fitness (Falconer, 1964), particularly when some environmental resource becomes limiting (Wool and Sverdlov, 1976). Inbreeding can lead to a high degree of adaptation to local conditions, and the botanical concept of the locally adapted race or ecotype (Turesson, 1922) may well be relevant to some animals. The extent to which local adaptation occurs and is maintained by inbreeding in species such as fallow deer is not known but should obviously be an important consideration in wildlife management (Smith et al., 1976). It is interesting to note that the controversy over whether to preserve an inbred stock or to introduce fresh blood into a deer park is over a century old (Shirley, 1867); because a high degree of variation is to be expected between inbred lines, the answer must surely be to preserve healthy inbred stocks and only to outbreed if deleterious effects of inbreeding are apparent. 
Acknowledgments. - The first draft of the manuscript was greatly improved by discussion with Professor J. Maynard Smith of the University of Sussex. from whom I also learned that, as well as himself, the following workers have independently derived equations (I) and (2): Dr C. Packer of the University of Sussex, Dr G. A. Parker of the University of Liverpool and Mr J. Tooby of Harvard University.

\section{REFERENCES}

BENGTSSON, B. 1978. Avoid inbreeding: at what cost? 7. theor. Biol., 73, 439-444. BERRY, R. J. 1977. Inheritance and Natural History. London, Collins.

Bertram, B. C. R. 1976. Kin selection in lions and in evolution. In Growing Points in Ethology, ed. P. P. G. Bateson and R. A. Hinde, 281-301. Cambridge University Press, Cambridge.

Bodmer, W. F., AND CAVAlli-sforza, L. L. 1976. Genetics, Evolution and Man. Freeman, San Francisco.

BRADShaW, A. D. 1971. Plant evolution in extreme environments. In Ecological Genetics and Evolution, ed. E. R. Creed, 20-50. Blackwell, Oxford.

CAvalli-sforza, L. L., AND Bodmer, w. w. 1971. The Genetics of Human Populations. Freeman, San Francisco.

Chapman, D., AND chapman, N. 1975. Fallow Deer. Dalton, Lavenham.

CHRISTIANSEN, F. B., AND FRYDENBERG, O. 1973. Selection component analysis of natural polymorphisms using population samples including mother-offspring combinations. Theor. Popul. Biol., 4, 424-445.

CLUTTON-BROCK, T. H., AND HARVEY, P. H. 1976. Evolutionary rules and primate societies. In Growing Points in Ethology, ed. P. P. G. Bateson and R. A. Hinde, 195-237. Cambridge University Press, Cambridge.

CLUTTON-BROCK, T. H., AND HARVEY, P. H. 1978. Mammals, resources and reproductive strategies. Nature, Lond., 273, 191-195.

COX, C. R., AND LE BOEUF, в. J. 1977. Female incitation of male competition: a mechanism in sexual selection. Amer. Natur., 111, 317-335.

FAlCONER, D. s. 1964. Introduction to Quantitative Genetics. Oliver and Boyd, Edinburgh.

hamilton, w. D. 1964. The genetical evolution of social behaviour, I and II. 7 . theor. Biol., 7, 1-16 and 17-51.

HAWKINS, R. E., AND KLIMSTRA, W. D. 1970. A preliminary study of the social organisation of white-tailed deer. 7. Wildl. Manage., 34, 407-419.

HOWARD, W. E. 1949. Dispersal, amount of inbreeding, and longevity in a local population of Prairie Deermice on the George Reserve, Southern Michigan. Contr. Lab. Vert. Biol. Univ. Mich., 43, 1-50.

ITANI, J. 1972. A preliminary essay on the relationship between social organisation and incest avoidance in non-human primates. In Primate Socialisation, ed. F. E. Poirier, 165-171. Random House, New York.

LEWONTIN, R. C., AND DUNN, L. C. 1960. The evolutionary dynamics of a polymorphism in the house mouse. Genetics, 45, 702-722.

MCMAHAN, P. 1978. Natural history of the coyote. In Wolf and Man, ed. R. L. Hall and H. S. Sharpe, 41-54. Academic Press, New York.

MAYNARD Smith, J. 1964. Group selection and kin selection. Nature, Lond., 201, 1145-1147.

maxNARD SMIth, J. 1977a. Parental investment: a prospective analysis. Animal Behav., $25,1-9$.

MAYNARD sMrth, J. 1977b. The sex habit in plants and animals. In Measuring Selection in Natural Populations, ed. F. B. Christiansen and T. M. Fenchel. 315-331. SpringerVerlag, Berlin.

muller, H. J. 1950. Our load of mutations. Am. 7. hum. Genet., 2, 111-176.

ORIANS, G. H. 1969. On the evolution of mating systems in birds and mammals. Amer. Natur., 103, 589-603.

SELANDER, R. K. 1970. Behaviour and genetic variation in natural populations. Am. Zool., 10, 53-66.

SHIRLEy, E. P. 1867. Some Account of English Deer Parks with notes on the Management of Deer. Murray, London.

Smith, м. H., hillestad, H. O., Manlove, M. N., AND MaRchinton, R. L. 1976 . Use of population genetics data for the management of fish and wildlife populations. In Trans 41st North Am. Wildl. and nat. Res. Conf., Washington, D.C. March 21-25 1976, ed. K. Sabol. 119-133. 
SмITH, R. H. 1978. Fallow deer. Reading Naturalist, 30, 12-14.

SMITH, R. H., JOHNSON, E., HORNBY, J. E., AND HOLT, A. C. E. 1978. Long-haired fallow deer. Rep. Forest Res., Lond., 1978, 57-58.

sulltvan, J. O. 1978. Variability in the wolf, a group hunter. In Wolf and Man, ed. R. L. Hall and H. S. Sharpe, 31-40. Academic Press, New York.

TURESSON, G. 1922. The genotypical response of the plant species to the habitat. Hereditas, $3,211-250$.

wallace, в. 1968. Topics in Population Genetics. Norton, New York.

wilson, E. o. 1975. Sociobiology: the New Synthesis. Harvard University Press, Cambridge, (Mass).

WILsON, E. O. 1976. The central problems of sociobiology. In Theoretical Ecology: Principles and Applications, ed. R. M. May, 205-217. Blackwell, Oxford.

wOOL, D., AND SVERDLOV, E. 1976. Sib-mating populations in an unpredictable environment: effects on components of fitness. Evolution, 30, 119-129. 